\title{
Growth, Entrepreneurship, and Risk-Tolerance: A Risk-Income Paradox*
}

\author{
Ranoua Bouchouicha ${ }^{\dagger}$
}

Ferdinand M. Vieider ${ }^{\ddagger}$

May 15, 2019

\begin{abstract}
Recent papers have modeled the prevalence of risk-tolerance as shaped by growth, making testable predictions about the distribution of risk-tolerance across the globe. We test these predictions using a dataset containing a survey question capturing people's risk-tolerance for representative samples from 78 countries. We find a negative between-country correlation between risk-tolerance and GDP per capita. Together with the positive within-country correlation between risk-tolerance and income, this results in a risk-income paradox. We further find a negative interaction effect of risk-tolerance and GDP on fertility. These findings provide support for endogenous-preference models of economic growth.
\end{abstract}

Keywords: risk-tolerance; development; growth; risk-income paradox;

JEL-classification: D01, D03, D81, E03, O10

${ }^{*}$ The experimental validation contained in this paper was financed by the German Science Foundation (DFG) as part of project VI 692/1-1 on "Risk preferences and economic behavior: Experimental evidence from the field". We are grateful to Matthias Doepke, Oded Galor, Thomas Dohmen, and Thomas Epper for helpful comments. All errors remain our own.

${ }^{\dagger}$ Henley Business School, University of Reading, UK. Email: r.bouchouicha@reading.ac.uk

${ }^{\ddagger}$ Department of Economics, Ghent University, Belgium; email: ferdinand.vieider@ugent.be 


\section{Introduction}

Individual preferences play a central role for economic decisions and outcomes. Recently, a consensus has started to emerge that preferences are malleable, abandoning the 'black box' idea that we do not care about where supposedly unchangeable preferences come from (Bowles, 1998). This raises the important question of what may determine the distribution of preferences across individuals and across countries.

Several recent papers have modeled the evolutionary origins of preferences. Galor and Moav (2002) modeled the predisposition towards child quality as a consequence of the evolutionary pressures prevailing in the Malthusian era. Galor and Michalopoulos (2012) and Doepke and Zilibotti (2014) modeled the prevalence of risk-tolerance in a country as shaped by growth processes. Galor and Özak (2016) modeled the contemporary distribution of time preferences as shaped by agricultural yields in the Malthusian era. Galor and Savitskiy (2018) presented an evolutionary model on the origins of loss aversion, predicting that individuals who originate from parts of the world characterised by climatic shocks that are correlated across space and time will be more loss averse than individuals from regions with more volatile climatic shocks.

Several attempts have been made to test the predictions emerging from these models. The predictions of Galor and Moav (2002) have been tested by Galor and Klemp (2019) using data from Quebec from the 1600s and 1700s. The authors showed that predisposition towards child quality, reflected in intermediate levels of fecundity, led to higher levels of long-run reproductive success than the highest fecundity levels. Galor and Özak (2016) presented a test of their own model, showing that agricultural yield pre1500 predicts contemporary distributions in long-term orientation. Galor and Savitskiy (2018) tested their own predictions using proxies for loss aversion such as a preference for job security. Using second generation migrants, they were able to show an effect of the nature of shocks on loss aversion while excluding direct influences of geography. Ashraf and Galor (2018) present an overview of the literature pointing to the importance of evolutionary forces for comparative development.

We add to this literature by testing the predictions on the global distribution of risk preferences of Galor and Michalopoulos (2012) and Doepke and Zilibotti (2014). Galor and Michalopoulos (2012) present an evolutionary model in which the prevalence of risk-tolerance in a country is driven by reproductive success. In early, Malthusian phases 
of development, risk-tolerance confers an evolutionary advantage. This evolutionary advantage is reversed as income per capita rises because of the increasing cost of children relative to consumption, leading risk-tolerant parents to substitute quality for quantity of children (Becker, 1960; Becker, Murphy and Tamura, 1990). Paired with the intergenerational transmission of risk-tolerance (Kimball, Sahm and Shapiro, 2009; Dohmen, Falk, Huffman and Sunde, 2012), this leads to the prediction of a shift in the composition of the population as countries grow rich. A direct test of the theory is provided by the association between risk-tolerance and fertility. In particular, the theory predicts a positive correlation between risk-tolerance and the number of children in Malthusian economies, and a negative correlation in rich countries, resulting in a negative interaction effect of GDP per capita and risk-tolerance on the number of children.

Doepke and Zilibotti (2014) provide a complementary account focusing on the specific mechanism shaping preferences, identified in conscious socialization decisions of parents to prepare their children for the prevailing conditions (see also Doepke and Zilibotti, 2008 and Doepke and Zilibotti, 2017). They predict that the prevalence of risk-tolerance in an economy is determined by the entrepreneurial wage premium - the extent to which entrepreneurs earn higher incomes than workers. This prediction results from the observation that such a wage premium constitutes an incentive for parents to instill the necessary risk-tolerance into their children for them to become entrepreneurs. Doepke and Zilibotti (2014) further predict that the prevalence of risk-tolerance depends on past growth levels. In many respects, the predictions derived from this model are complementary to those of Galor and Michalopoulos (2012), with the most significant differences concerning the mechanism through which risk-tolerance is transmitted. ${ }^{1}$

We set out to empirically document patterns of risk-tolerance across the globe. We use a dataset containing representative samples from 78 countries, with a median sample size of 1200 respondents per country and a total of 107,000 respondents, making this the largest comparative dataset on risk-tolerance to date. ${ }^{2}$ The dataset contains a

\footnotetext{
${ }^{1}$ Galor and Michalopoulos (2012) do not take a stand on the trasmission mechanism, acknowledging specifically that the theory is compatible with either genetic or cultural transmission (see their footnote 4). Transmission of preferences must, however, be prevalently vertical from parents to children, given the importance of fertility in shifting the composition of the population in terms of risk-tolerant types. Doepke and Zilibotti (2014), on the other hand, focus specifically on the transmission mechanism, identified in conscious socialization decisions by parents, but do not explicitly model the fertility channel.

${ }^{2}$ Most previous comparative datasets rely on student samples, thus potentially being affected by selection effects and not permitting to draw inferences on population-wide patterns (see Rieger, Wang and Hens, 2014, and L'Haridon and Vieider, 2019). An exception to this rule are the representative data described by Falk, Becker, Dohmen, Enke, Huffman and Sunde (2018). We will compare our results to
} 
survey question on respondents' risk-tolerance. We allay concerns about the economic significance of our survey question by showing that it predicts incentivized choices over financial lotteries. In addition to this validation emulating previous validation exercises (Dohmen, Falk, Huffman, Sunde, Schupp and Wagner, 2011; Hardeweg, Menkhoff and Waibel, 2013; Galizzi, Machado and Miniaci, 2016), we further validate the question at the macroeconomic level by correlating it with the aggregate, incentivized country-level data from Vieider, Lefebvre, Bouchouicha, Chmura, Hakimov, Krawczyk and Martinsson (2015). We find strong and significant correlations at both levels, pointing to a remarkable stability of the underlying behavioral trait of risk-tolerance.

We start by showing that risk-tolerance is positively correlated with entrepreneurship in our data, as postulated by both Galor and Michalopoulos (2012) and Doepke and Zilibotti (2014). We also find a strong positive correlation between income and risktolerance within countries, thus replicating another stylized finding from the literature. More originally, we show that between countries aggregate risk-tolerance shows a negative correlation with GDP per capita, with poor countries displaying higher aggregate levels of risk-tolerance than rich countries. We show this correlation to be stable to the inclusion of a wide variety of geographic, institutional, and genetic controls. Together with the positive within-country correlation between risk-tolerance and income, which we find to hold across both rich and poor countries, this gives rise to a risk-income paradox. This paradox rules out simple intuitive accounts of the correlation between income and risktolerance, given the different directions of the correlation within and between countries.

We then proceed to separately test some of the central mechanisms underlying the two models. We find only weak evidence for a correlation of risk-tolerance with either the entrepreneurship wage premium or past growth, as predicted by Doepke and Zilibotti (2014). We do, on the other hand, find considerable support for the importance of the fertility channel as a transmission mechanism for risk-tolerance, as postulated by Galor and Michalopoulos (2012). In particular, we find a strong negative interaction effect between GDP per capita and risk-tolerance on the number of children. This effect provides direct support for the importance of the fertility channel in determining the prevalence of risk-tolerant types in the population. Our results thus support endogenouspreference models in which preferences themselves may be shaped by market mechanisms.

This paper proceeds as follows. Section 2 derives the predictions in more detail. those based on the latter dataset below. 
Section 3 presents the data and the validation of the survey question, as well as discussing our empirical methodology. Section 4 presents the results. Section 5 provides a discussion of our results and concludes the paper.

\section{Derivation of hypotheses}

In the interest of clarity, we divide the presentation of the hypotheses into three subsections. The first discusses common premises to the two models we aim to test. Subsequently, we present the hypotheses derived from each one of the models in isolation. Some of the hypotheses derived from the two models will turn out to be the same, and we will show that both models can indeed account for the risk-income paradox. The mechanisms involved, however, are different. Presenting the hypotheses derived from the two models separately will thus help maintaining conceptual clarity.

\subsection{Common premises}

The importance of risk-tolerance for economic growth derives from its role as a driver of entrepreneurship, which is the premise underlying both of the models we aim to test. A correlation between risk-tolerance and entrepreneurship could be rationalized by a variety of models and mechanisms, so that its existence does not provide strong evidence for the specific theories. An absence of this relation in the data would, nevertheless, bode ill for the models we want to test. This results in our first prediction:

Prediction 1: Entrepreneurs are more risk-tolerant than workers.

We are by no means the first to test the correlation between risk-tolerance and entrepreneurship. Cramer, Hartog, Jonker and van Praag (2002) provided direct evidence on how self-employment is associated with higher risk-tolerance. Charles and Hurst (2003) showed that people who fall into the highest risk-tolerance category out of four are 50\% more likely to own a business than the mean. Falk et al. (2018) presented evidence from a global sample that risk-tolerance correlates positively both with business ownership and with plans to start a business. More in general, there is considerable evidence that risk-tolerance determines employment decisions. For instance, Bonin, Dohmen, Falk, Huffmann and Sunde (2007) showed that risk-tolerance correlates with sorting into more risky professions as well as with higher income (see also Shaw, 1996). 


\subsection{Hypotheses derived from Galor and Michalopoulos}

We start at the microeconomic level and examine the relationship between risk-tolerance and income. Predictions on a relationship between risk-tolerance and income are often intuitively founded, as well as being justifiable based on many theories. Simple intuitive accounts of the correlation, however, do not seem capable of organizing the risk-income paradox. Galor and Michalopoulos (2012) do not per se make predictions about the relationship between income and risk-tolerance. It is, however, straightforward to incorporate such a correlation into their model. ${ }^{3}$ Allowing for a positive correlation between risk-tolerance and income within countries creates a link to earlier models in the same research tradition (Galor and Weil, 2000; Galor and Moav, 2002). It further allows to connect the predictions to findings from economic history showing how reproductive success in Malthusian economies is positively linked to income and wealth (Clark and Hamilton, 2006; Clark, 2007; Goodman, Koupil and Lawson, 2012). In particular, entrepreneurial individuals will earn higher incomes on average, yielding the following prediction:

Prediction GM1: Within countries, risk-tolerance is positively correlated with income.

The evolutionary setup of Galor and Michalopoulos (2012) can furthermore account for a between-country distribution of risk-tolerance that differs markedly from its withincountry prediction, thus resolving the paradox. Risk-tolerance confers an evolutionary advantage in economies in early, Malthusian, stages of development, which is later reversed in advanced economies. The reversal is driven by the relative cost of consumption and children, with higher incomes per capita in advanced economies making children relatively more expensive (Becker, 1960; Becker et al., 1990). Risk-tolerant individuals respond more readily to relative costs, thus prioritizing children when income is low, but being the first to substitute consumption for children as income increases. Given the positive link between risk-tolerance and fertility in Malthusian economies, and given the inversion of this correlation in advanced economies, one would expect a larger proportion of risk-tolerant types in the populations of poor countries than in those of rich countries.

\footnotetext{
${ }^{3}$ This possibility is explicitly acknowledged by the authors, with the consequence that "allowing for entrepreneurial activity to generate higher expected income, in an era in which the latter is converted into larger number of surviving offspring, would accentuate the evolutionary advantage of the growthpromoting type." (Galor and Michalopoulos, 2012, footnote 16).
} 
This prediction emerges because preferences are transmitted from parents to children, and given the differential fertility rates of the risk-tolerant types in different phases of development. It ultimately constitutes a reflection of the difference in the time passed since the fertility transition in rich and poor countries. This difference in risk-tolerant traits across countries can be seen as one factor contributing to convergence across countries. ${ }^{4}$ This leads us to the following prediction:

Prediction GM2: Aggregate risk-tolerance correlates negatively with GDP per capita. Together with prediction GM1, this prediction accounts for the risk-income paradox.

In the model of Galor and Michalopoulos (2012), fertility decisions play a central role. In the Malthusian steady state, risk-tolerance is predicted to correlate positively with the number of children, while this correlation ought to be negative in advanced economies. Given that all countries have undergone the fertility transition by now (Cohen, 1998; Garenne and Joseph, 2002), turning this into a prediction that is testable on contemporaneous data requires weakening the hypothesis to a quantitative interaction of the risk-tolerance-fertility correlation with GDP per capita. This yields the following prediction:

Prediction GM3: There is a negative interaction effect of risk-tolerance and

GDP per capita on the number of children in a cross-section of countries.

This last prediction about the transmission mechanism is indeed central to the model. Galor and Michalopoulos (2012) themselves point out that "the predictions of the theory regarding the reversal in the evolutionary advantage of entrepreneurial, risk-tolerant individuals in more advanced stages of development could be examined based on the effect of the degree of risk aversion on fertility choices in contemporary developed and less developed economies" (pp. 761-762).

\subsection{Hypotheses derived from Doepke and Zilibotti}

We again start from the correlation between risk-tolerance and income at the individual level. In the model of Doepke and Zilibotti (2014), risk-tolerant individuals become

\footnotetext{
${ }^{4}$ The fact that we may not see convergence happening in reality may be due to convergence being conditional on a number of other factors, such as education and institutions; see e.g. Barro (1991) and Sala-i Martin (1996).
} 
entrepreneurs because entrepreneurs earn higher incomes than workers on average (although they may end up with lower incomes if their venture does not prove successful):

Prediction DZ1: Within countries, risk-tolerance is positively correlated with income.

The transmission of preferences is consciously determined by parents in order to prepare their children for the economic circumstances they will face as adults - one of the main differences from the model of Galor and Michalopoulos (2012). ${ }^{5}$ The likelihood of instilling risk-tolerance into one's offspring - and hence the prevalence of risk-tolerance in the economy - may explicitly depend on the wage premium earned by entrepreneurs relative to workers. This is driven by the observation that parents care about the economic prospects of their children, thus trying to prepare them for the economic circumstances they will face as adults (Bisin and Verdier, 2001). These conditions are forecast in a naive way as equal to current economic conditions. This results in differential long-run equilibria across countries, characterized by different levels of risk-tolerance in a population. This leads to the following prediction:

Prediction DZ2: Between countries, the prevalence of risk-tolerance correlates with the entrepreneurial wage premium.

The mechanism underlying the transmission of risk preferences just described has also consequences at the macro level. It directly results in the prediction that the growth rate of a country feeds back into the prevalence of entrepreneurship in an economy. This is because parents living in highly entrepreneurial economies, driven by the entrepreneurial wage premium as detailed in prediction DZ2, will in turn expect their children to become entrepreneurs, and will thus try and instill the necessary risk-tolerance into them. ${ }^{6}$ This will then lead to differences in equilibrium growth rates between countries, which are maintained over the long run. This allows us to derive the following testable prediction:

\footnotetext{
${ }^{5}$ Klasing (2014) proposed a model making similar predictions, that is however more difficult to test empirically. We will thus focus here on the model by Doepke and Zilibotti.

${ }^{6}$ Notice that this prediction is derived in equilibrium, where entrepreneurship fuels growth, and growth in turn creates incentives for parents to socialize children to be entrepreneurial. That also means that the prediction may not be expected to hold in some countries if the link between entrepreneurship and growth is broken while entrepreneurship itself is driven by other factors.
} 
Prediction DZ3: Past economic growth is positively correlated with the level of risk-tolerance in a country.

The relationship with GDP is not explicitly discussed in the model. However, one of the reasons why parents might wish to instill risk-tolerance into their offspring is to prepare them for the riskiness of the environment they will face in general, beyond the payoffs to entrepreneurship. ${ }^{7}$ The model can thus account for the risk-income paradox. The negative correlation of risk-tolerance with GDP per capita is in this case predicted because of the close association of the latter with riskiness of the environment, as measured for instance by the insecurity of property rights, a prevalence of informal work relationships, epidemiological and traffic risks, and so forth:

Prediction DZ4: Aggregate risk-tolerance correlates negatively with GDP per capita. Together with prediction DZ1, this gives rise to a risk-income paradox.

Before proceeding to testing the relations just discussed, let us try and put the two different theories into perspective. We have already seen that while some of the predictions are the same - such as the prediction of a risk-income paradox - the reasons underlying these predictions can be quite different. Testing the mechanisms underlying the predictions is thus particularly important. Let us also reiterate that we are not trying to pitch the two theories against each other. Rather, we want to try and test the predictions of both theories because they afford largely complementary insights into what may shape the prevalence of risk-tolerance within and between countries.

\section{Data and Methodology}

\subsection{The dataset}

We use data from the World Value Survey ( WVS ) collected between 2005 and 2014. A question on risk-tolerance was first introduced in wave 5, collected from 2005-2010. That wave contains data on risk attitudes and income for 51 countries. We further supplement

\footnotetext{
${ }^{7}$ We are grateful to Matthias Doepke for pointing this out in private correspondence.
} 
these data with data from wave 6 , collected between 2010-2014. This leaves us with a total of 78 countries. Some countries were included in both waves, and we use only the data from wave 5 for those countries to avoid imbalances in samples across countries. For the 33 countries included in both wave 5 and wave 6 , we find no significant difference in aggregate risk-tolerance across waves. The combination of the two waves serves purely to obtain the maximum number of countries. Our main results remain stable if we only use countries from wave 5 or from wave 6 instead of the combined sample, or indeed if we use all the data from both waves (see Online Appendix).

The surveys are designed to be representative of the adult population of each country. The median sample size per country is 1200 respondents. Samples are obtained by stratifying a country geographically and by size of community, and then randomly sampling locations within those communities. Details may differ somewhat by country, and are described in the WVS documentation. Sampling weights are provided in each country data set to correct for sampling imbalances, and we will use those weights throughout our analysis. We combine the WVS data set with macroeconomic data from various sources. We obtain macroeconomic data on GDP, oil rents, growth, and Gini coefficients from the World Bank tables. Usually, values for 2010, the year intermediate between the two waves, are used as our main data source. The effects remain unaffected if we use only data from 2005 (the beginning of wave 5) instead, or if we use means over several years. For the Gini coefficient, we use the closest coefficient available in case the Gini is unavailable for 2010. Gini coefficients are not available for many countries in the World Bank data. Where that is the case, we first tried to obtain an estimate from the CIA Factbook. If that failed too, we looked at UNDP data or searched the internet for other sources. In addition, we combined the data with the data set constructed by Ashraf and Galor (2013), containing a host of data on genetic differences, institutional variables, and geographical indicators. These will be described in more detail as the need arises.

\subsection{Descriptives and validation of risk preference question}

We start by validating the question capturing risk-tolerance. The question records answers on a Likert scale, allowing for a qualitative categorisation of risk-tolerance. Qualitative scales to capture risk attitudes have been validated in a representative sample of Germany by Dohmen et al. (2011). They were further validated in a large rural sample 
in Thailand by Hardeweg et al. (2013). Lönnqvist, Verkasalo, Walkowitz and Wichardt (2015) found a survey question to outperform an incentivised question in test-retest reliability (see also Galizzi et al., 2016). Using student data from 30 countries, Vieider et al. (2015) showed that declared willingness to take risk in general and in financial matters correlates significantly with incentivised measures of risk (known probabilities) and uncertainty (unknown or vague probabilities) preferences, and for both gains and losses. This correlation was found not only to hold at the microeconomic level for most countries, but also at the aggregate level between countries.

The studies just mentioned validated a particular question, measuring the 'general willingness to take risk' of respondents, with a response scale from 0 to 10 . In addition, some of them validated a question asking for the willingness to take risks in specific contexts, amongst which the willingness to take risks in financial matters performed particularly well. The question used in the WVS is different. It reads as follows:

Now I will briefly describe some people. Would you please indicate for each description whether that person is very much like you, like you, somewhat like you, not like you, or not at all like you?

\begin{tabular}{lcccccc}
\hline & $\begin{array}{c}\text { very } \\
\text { much } \\
\text { like me }\end{array}$ & $\begin{array}{c}\text { like } \\
\text { me }\end{array}$ & $\begin{array}{c}\text { Some- } \\
\text { what } \\
\text { like me }\end{array}$ & $\begin{array}{c}\text { A little } \\
\text { like me }\end{array}$ & $\begin{array}{c}\text { Not } \\
\text { like me }\end{array}$ & $\begin{array}{c}\text { Not at } \\
\text { all } \\
\text { like me }\end{array}$ \\
$\begin{array}{l}\text { Adventure and taking risks are important } \\
\text { to this person, to have an exciting life }\end{array}$ & $\mathrm{O}$ & $\mathrm{O}$ & $\mathrm{O}$ & $\mathrm{O}$ & $\mathrm{O}$ & $\mathrm{O}$ \\
\hline
\end{tabular}

The answers to this question are coded from 1 to 6 . We reverse-code the question and shall simply refer to this measure as 'risk-tolerance'. Figure 1 shows the countries included in the dataset together with their level of risk-tolerance. The data cover a total of 78 countries, and are representative within each country as well as providing geographical and economic coverage of the whole world. Overall, the data cover $84 \%$ of the world's population, and $89 \%$ of its economic output.

Given the different formulation of this question relative to previously used survey questions, it appears paramount to investigate whether it predicts risk preferences in the sense usually intended by economists. To this end, we administered the survey question together with an incentivised question to measure risk preferences to a sample representative of the population of one district in Karnataka state, India. The incentivised task consisted in eliciting the sure amount of money that is considered equally good as a prospect giving a $50 \%$ probability of winning 450 Rupees or else nothing. The 


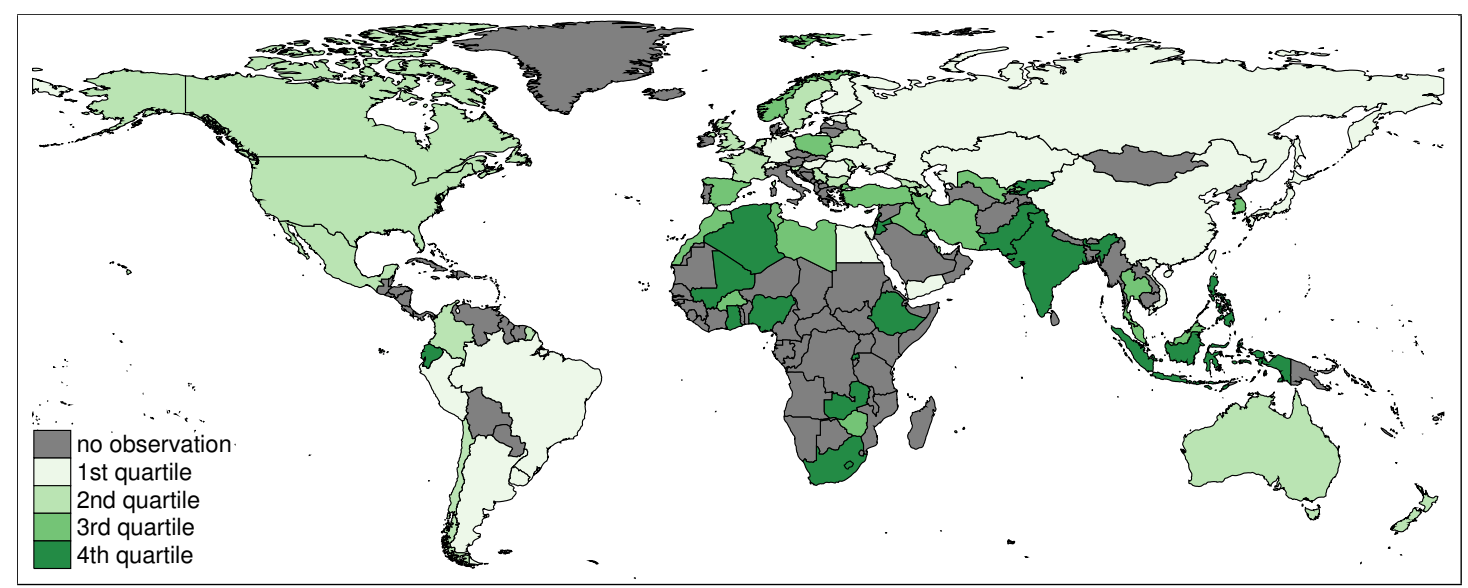

Figure 1: World map of risk-tolerance

sure amount varied in equal steps of 45 Rupees between the lowest and highest amount of the prospect in a choice list. ${ }^{8}$ Table 1 shows the results. Regressions I-IV regress the certainty equivalent on the survey question. Subsequent regressions add additional controls on demographics (age, sex, and literacy), recent exposure to shocks (weather shocks, violence, stress, hunger, and health), and cognitive ability (measured through a battery of raven tests and numeracy questions). In all regressions the survey question is a clear predictor of financial risk preferences as measured through the certainty equivalent. Regressions V and VI further regress answers to the general-willingness-totake-risks question on the survey question used in this paper. Once again, we find that our survey question predicts answers to that question. Comparing the predictive performance of the two survey questions, we come to the conclusion that the WVS question predicts incentivized decisions better than the general-willingness-to-take-risks question.

The second approach we follow is to validate the responses at the macro-economic level. We use the aggregate data from Vieider et al. (2015) to test whether the aggregate country-level results from the WVS data correlate with those results. Notice that this is quite a hard test, inasmuch as - contrary to other validation exercises - the correlation is between aggregate measures obtained from different subject pools in very different settings. The correlation between the WVS question and the various questions used by Vieider et al. (2015) are shown in figure 2. There is an overlap of 23 countries between the two datasets. Panel 2(a) displays the correlation between the aggregate answer to

\footnotetext{
${ }^{8}$ The choices were represented physically using colored balls and banknotes, and were shown to subjects one by one in individual interviews. At the end of the experiment, one of the decisions was randomly extracted to be played for real money - the standard procedure in this kind of task.
} 
Table 1: Validation of survey question

\begin{tabular}{lccccccc}
\hline & \multicolumn{5}{c}{ certainty equivalent } & & \multicolumn{2}{c}{ willingness to take risk } \\
\cline { 2 - 4 } & I & II & III & IV & & V & VI \\
\hline risk-tolerance & $8.369^{* *}$ & $8.352^{* *}$ & $7.619^{* *}$ & $7.020^{* *}$ & & $0.293^{* * *}$ & $0.265^{* * *}$ \\
& $(3.401)$ & $(3.451)$ & $(3.451)$ & $(3.440)$ & & $(0.051)$ & $(0.052)$ \\
demographics & & $\checkmark$ & $\checkmark$ & $\checkmark$ & & $\checkmark$ \\
shocks & & & & & & $\checkmark$ \\
cognitive ability & & & & & & $\checkmark$ \\
Constant & $242.350^{* * *}$ & $257.727^{* * *}$ & $232.558^{* * *}$ & $195.555^{* * *}$ & & $-3.210^{* * *}$ & $-2.627^{* * *}$ \\
& $(13.950)$ & $(20.868)$ & $(24.709)$ & $(33.914)$ & & $(0.258)$ & $(0.531)$ \\
\hline log sigma & $4.793^{* * *}$ & $4.790^{* * *}$ & $4.783^{* * *}$ & $4.777^{* * *}$ & & \\
& $(0.034)$ & $(0.034)$ & $(0.034)$ & $(0.034)$ & & \\
ll & -1097.186 & -1093.233 & -1090.043 & -1087.335 & & -1003.114 & -979.864 \\
Observations & 455 & 454 & 454 & 454 & 455 & 454 \\
\hline
\end{tabular}

Robust, heteroscedasticity-resistant standard errors are reported in parentheses. Stars signal significance at the following levels: ${ }^{*} p<0.10,{ }^{* *} p<0.05$, ${ }^{* * *} p<0.01$. Regressions I to IV have the certainty equivalent as a dependent variable, and use interval regression techniques to take into account the interval information obtained about risk preferences. Regressions V and VI have the answer about one's general willingness to take risk as a dependent variable, and use ordered logit regressions. All results are stable if we use OLS regressions instead.

the WVS question and the relative risk premium $(R R P)$ for risky gains. ${ }^{9}$

The correlation coefficient is substantial, and statistically significant. ${ }^{10}$ This is quite remarkable, keeping in mind the small sample size. Panel 2(b) shows the same correlation using the RRP for gains and uncertainty, i.e. the case in which probabilities are unknown or vague. We again find a sizeable correlation. The stronger correlation for uncertainty than for risk corresponds to the observation by Vieider et al. (2015) that survey measures seem to show the strongest correlation with measures for which exact probabilities are not known (a concept that is close to real-world concepts of 'risk'). Panels 2(c) and 2(d) show the correlations for incentivized measures for losses, for risk and uncertainty respectively. The correlation is of the same order of magnitude as the one found by Vieider et al. (2015) within subjects. Finally, panel 2(e) shows the correlations with the answers to the question on general willingness to take risks, and panel 2(f) shows the equivalent correlation for willingness to take risks in financial matters. Both correlations are strong and highly significant. The correlation with the question on financial risk taking is particularly strong at 0.6 .

These results show a remarkable stability of risk preferences at the country level, across different measurement types (hypothetical qualitative and incentivised quantitative measures), different outcome domains (gains and losses), and different uncertainty

\footnotetext{
${ }^{9}$ The RRP is defined as the certainty equivalent minus the expected value, normalised by the absolute expected value.

${ }^{10}$ We use Pearson correlations throughout, since we are interested in the strength of the effects beyond mere ranks, and since the use of aggregate quantities lowers the incidence of outliers. Results using Spearman rank-correlations instead are qualitatively similar unless stated otherwise.
} 


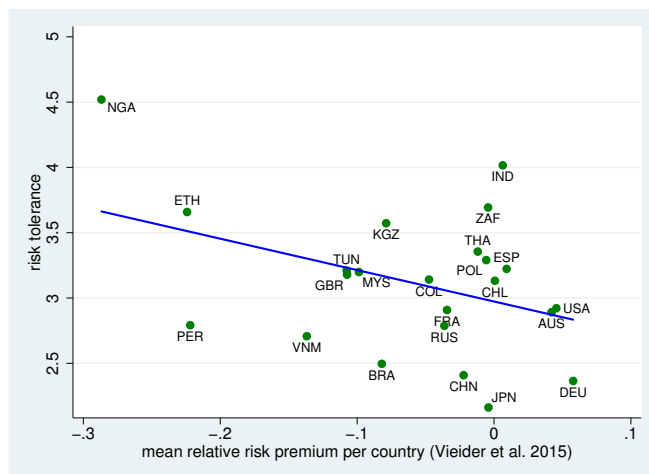

(a) Risky gains: $r=-0.397, p=0.031$

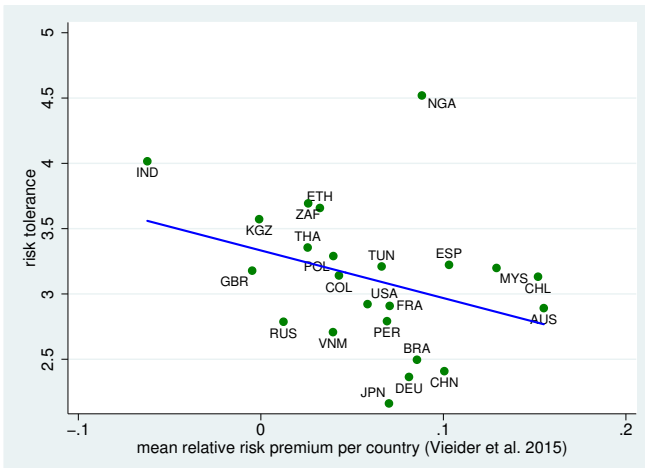

(c) Risky losses: $r=-0.340, p=0.055$

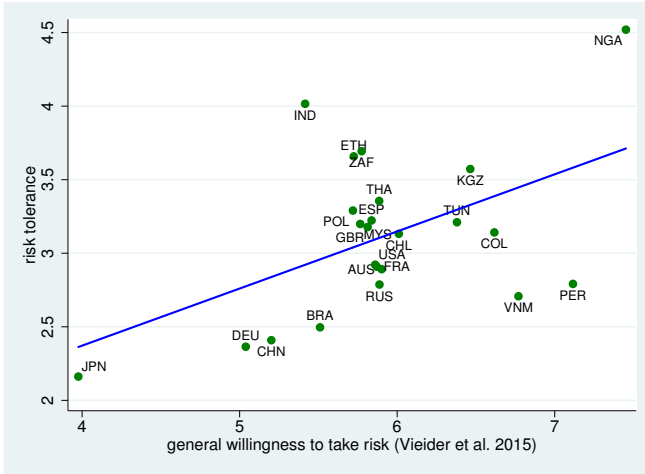

(e) General question: $r=0.504, p=0.007$

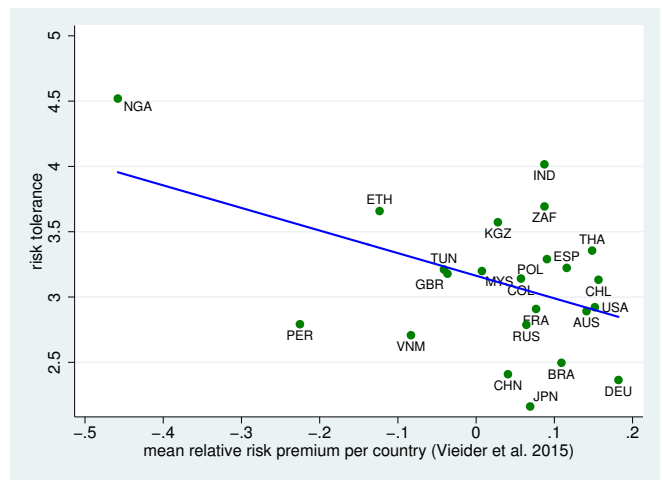

(b) Uncertain gains: $r=-0.456, p=0.014$

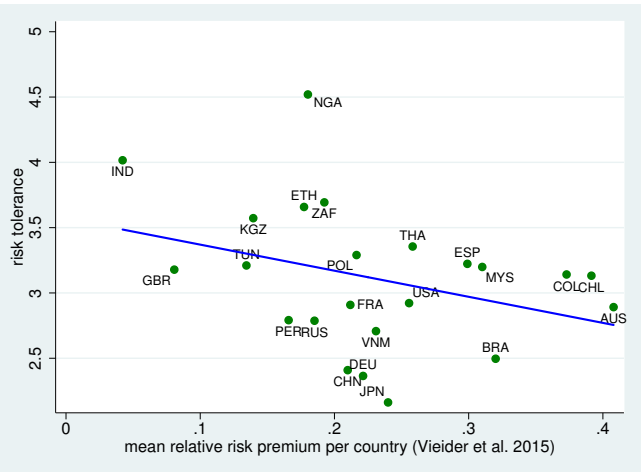

(d) Uncertain losses: $r=-0.337, p=0.058$

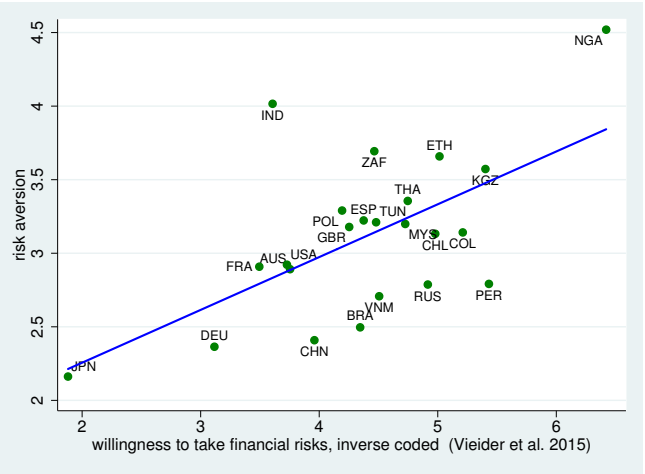

(f) Financial question: $r=0.602, p=0.001$

Figure 2: Macro-correlation with measures from Vieider et al. 2015

sources (known and unknown probabilities). This is all the more remarkable considering that the data in Vieider et al. (2015) were collected only with university students, while the data from the WVS derive from representative population samples in each country. This further corroborates findings showing the similarity in aggregate risk preferences between students and rural population samples reported by Vieider, Martinsson, Pham Khanh and Truong (2019) and Vieider, Beyene, Bluffstone, Dissanayake, Gebreegziabher, Martinsson and Mekonnen (2018) for Vietnam and Ethiopia respectively. 
Similar conclusions were reached by Andersen, Harrison, Lau and Rutström (2010) for Denmark and Fehr-Duda and Epper (2012) for Switzerland. Most importantly, however, this validates the WVS measure of risk-tolerance as a proxy for financial risk aversion measured in incentivized experiments.

\subsection{Methodology}

We use a hierarchical model to analyse the data. This method is specifically designed to analyse data where several levels of analysis overlap, in which case OLS generally results in biased estimates (Moulton, 1986). It provides standard errors corrected for the multilevel structure (Zeger, Liang and Albert, 1988), which makes them more conservative than estimates obtained directly from individual-level regressions. Compared to estimations using aggregate data, this approach avoids the so-called ecological fallacy, which occurs when proportions of individual level characteristics are entered into aggregate regressions (Robinson, 1950).

The hierarchical regression technique we use results in a generalization of linear regression techniques whereby the residuals are not independent, but may be correlated within higher level units (in our case, the different countries). We thus estimate a model of the following form:

$$
r_{i j}=X_{i j} \beta+u_{j}+\epsilon_{i j},
$$

where $r$ indicates risk-tolerance, and the subscripts $i$ and $j$ indicate our two levels of analysis - individuals and countries. The matrix $X$ of observable characteristics may contain indicators at the individual level or at the country level. This part of the estimation takes the form of a standard OLS model. In multiple regression, the vector $\beta$ will consist of an intercept, $\beta_{0}$, and a number of regression coefficients $\beta_{k}$ equal in number to the number of independent variables.

\section{Results}

We present the results in several steps. We start by examining the role of risk-tolerance as a determinant of entrepreneurship, and the microeconomic relationship between risktolerance and income. We then present the risk-income paradox, juxtaposing the micro 
and macro results directly. We subsequently continue our analysis with some tests of the mechanisms postulated by the different models.

\subsection{Microevidence on risk-tolerance, entrepreneurship, and income}

We start by examining the evidence on the correlation of risk-tolerance with entrepreneurship and with personal income at the microeconomic level. These correlations are closely related from a conceptual point of view according to the model, which makes it natural to present them together. We would also like to reiterate how these correlations cannot be construed as definite tests of the theories, since such relationships can be conceptualized based on a variety of different models. Nor is the evidence presented in this section very novel, since both correlations have been discussed many times before. Nevertheless, we deem it desirable to test them in our data, both because these correlations are at times still contested by some scholars ${ }^{11}$, and because their absence would bode ill for our enterprise of testing some of the more original predictions of the two models.

We start from the correlation between risk-tolerance and entrepreneurship. We use a question in the WVS where people declare whether they are self-employed, work for the government, private firms, or in the nongovernmental sector. Table 2 shows a number of regressions of a dummy variable indicating self-employment on risk-tolerance. Regression I establishes the basic relationship — risk-tolerance shows a clear and highly significant positive correlation with entrepreneurship. Regression II adds a number of individuallevel variables, including age and gender, as well as controls of educational attainment and marital status. The correlation between risk-tolerance and self-employment remains stable, and results even somewhat reinforced.

Regression III adds personal income to the regression. This control is essential in order to ensure that the correlation is not spurious, and purely driven by the higher income earned by entrepreneurs in most countries. This assumes that risk-tolerance and income are themselves rather strongly correlated - an issue that we will examine shortly. Risk-tolerance remains a strong predictor of entrepreneurship even after controlling for

\footnotetext{
${ }^{11}$ We included a brief literature review of the correlation of risk-tolerance and entrepreneurship above. In terms of the correlation between risk-tolerance and income, many studies have found a positive relationship between risk-tolerance and income (Dohmen et al., 2011; Gloede, Menkhoff and Waibel, 2015; Hopland, Matsen and Strøm, 2016; Vieider et al., 2018; Falk et al., 2018), several others have found no correlation (Binswanger, 1980; Cardenas and Carpenter, 2013; Noussair, Trautmann and van de Kuilen, 2014), while others still have observed mixed results (Booij, Praag and van de Kuilen, 2010; Tanaka, Camerer and Nguyen, 2010; von Gaudecker, van Soest and Wengström, 2011). See Hopland et al. (2016) for a more in-depth review.
} 
Table 2: Determinants of entrepreneurship

\begin{tabular}{lcccc}
\hline dep. var: self-employed dummy & I & II & III & IV \\
\hline risk-tolerance (z-score) & $0.058^{* * *}$ & $0.071^{* * *}$ & $0.069^{* * *}$ & $0.067^{* * *}$ \\
& $(0.017)$ & $(0.018)$ & $(0.018)$ & $(0.019)$ \\
income (z-score) & & & $0.073^{* * *}$ & $0.067^{* * *}$ \\
& & & $(0.024)$ & $(0.024)$ \\
demographics & & $\checkmark$ & $\checkmark$ & $\checkmark$ \\
macro controls & & & & $\checkmark$ \\
Constant & $-2.375^{* * *}$ & $-1.744^{* * *}$ & $3.284^{* * *}$ & $2.078^{* *}$ \\
& $(0.136)$ & $(0.176)$ & $(0.177)$ & $(0.749)$ \\
\hline Observations & 105442 & 97143 & 97143 & 93924 \\
Countries & 78 & 78 & 75 & 75 \\
log-likelihood & -34230.210 & -29210.527 & -29193.698 & -28361.673 \\
\hline Robut, & & & &
\end{tabular}

Robust, heteroscedasticity-resistant standard errors are reported in parentheses. Stars signal significance at the following levels: ${ }^{*} p<0.10,{ }^{* *} p<0.05,{ }^{* * *} p<0.01$. Multilevel logistic regression is used throughout, with errors clustered according to the appropriate units of analysis (individuals, countries). Macro controls include GDP per capita and the Gini index, as well as a variety of institutional factors, such as legal origins and an indicator of democracy (see further below). The correlations shown are stable to using OLS regression instead of a logit model, and to using country fixed effects instead of the hierarchical model we employ here.

income, which itself shows the expected positive correlation with entrepreneurship. Regression IV adds a number of between-country controls, which do not significantly affect our conclusions. Overall, we thus find prediction 1 to be supported in our data.

We continue by looking at individual-level correlations of income with risk-tolerance. Our income variable takes the form of self-declared household income deciles. ${ }^{12}$ One might expect such a measure to be noisy, and indeed a Kolmogorov-Smirnoff test rejects a uniform distribution over the deciles $(p<0.001)$. Responses tend to be heaped towards the middle of the scale in most countries, with fewer responses in the lowest and highest categories (the Online Appendix provides graphs and a detailed analysis at both the aggregate and the country level). To validate our income measure, we use data from the European Social Survey (ESS) to correlate self-declared income deciles with absolute gross incomes. The results show that the two measures are significantly correlated in all 27 ESS countries. The correlations are moderately high, with a median correlation coefficient of 0.63 (see Online Appendix for details). To allay any remaining concerns about our income measure, we will further use social class as a stability control.

Table 3 shows regressions of risk-tolerance on a variety of individual characteris-

\footnotetext{
${ }^{12}$ The question reads as follows: "On this card is a scale of incomes on which 1 indicates the 'lowest income decile' and 10 the 'highest income decile' in your country. We would like to know in what group your household is. Please, specify the appropriate number, counting all wages, salaries, pensions and other incomes that come in."
} 
tics. ${ }^{13}$ Regression I uses income as the sole explanatory variable, and shows a clear positive correlation between risk-tolerance and income. Regression II adds a number of demographic controls. The income coefficient drops somewhat as a result of this, but nonetheless remains highly significant. The higher the level of education, the more risktolerant respondents are. There are two possible explanations for this. A straightforward explanation might be that risk-tolerance is positively correlated with cognitive ability (Dohmen, Falk, Huffman and Sunde, 2010; Benjamin, Brown and Shapiro, 2013), and that education serves as a proxy for cognitive ability. However, a recent investigation by Andersson, Tyran, Wengström and Holm (2016) cast doubt on the stability of the correlation between risk aversion and cognitive ability. An alternative explanation may then be that education proxies for income, given that measures of the latter are coarse and the two are typically highly correlated..$^{14}$

We find females to be significantly less risk-tolerant than males. This corresponds to standard findings in the literature (Croson and Gneezy, 2009), even though there may exist differences according to the measurement method employed (di Falco and Vieider, 2018). As expected, we find risk-tolerance to decrease in age. Risk-tolerance also strongly increases in age squared, however. In terms of marital status, every category except widowers are more risk-tolerant than the reference category of married people. This could be driven by people becoming less risk-tolerant when they marry (Görlitz and Tamm, 2015), but it may just as well result from less risk-tolerant people getting married more frequently or sooner in life, and then staying married with a higher likelihood (Schmidt, 2008).

Regression III further adds self-declared health state, encoded from 1 (very good) to 5 (very poor). Risk-tolerance decreases in this variable, indicating that people in poor health tend to be less risk-tolerant. Regression IV introduces a variable measuring life

\footnotetext{
${ }^{13}$ While the models we test predict causality to run from risk-tolerance to income passing through the entrepreneurship decision, in reality the causality in the risk-income relationship could run in either direction, and may well constitute a self-reinforcing feedback cycle. Indeed, the clear causal direction emerges from the model due to the abstraction from intergenerational transmission of wealth and skills, in addition to preferences. While most of the literature in labor economics emphasizes the causality from risk-tolerance to income passing through job choice (e g. Bonin et al., 2007), the literature in development economics generally emphasizes the opposite direction of causality (see Haushofer and Fehr, 2014, for a review). Making risk-tolerance the dependent variable allows us to examine the correlates of risk-tolerance, which is the truly novel measure at the center of our analysis. The correlation between income and risk-tolerance is unaffected if we take income as the dependent variable instead - a regression with income as the dependent variable is shown in the Online Appendix.

${ }^{14}$ Our data indeed show a substantial correlation between income decile and education. In particular, each higher level of education results in a significantly higher response on the income decile scale - see online appendix for the regression result.
} 
Table 3: Correlates of risk-tolerance at the individual level

\begin{tabular}{|c|c|c|c|c|c|}
\hline dep. var: risk-tolerance & I & II & III & IV & $\mathrm{V}$ \\
\hline income (z-score) & $\begin{array}{c}0.070^{* * *} \\
(0.009)\end{array}$ & $\begin{array}{c}0.047^{* * *} \\
(0.007)\end{array}$ & $\begin{array}{c}0.041^{* * *} \\
(0.006)\end{array}$ & $\begin{array}{c}0.038^{* * *} \\
(0.007)\end{array}$ & \\
\hline completed elementary & & $\begin{array}{c}0.013 \\
(0.022)\end{array}$ & $\begin{array}{c}0.008 \\
(0.022)\end{array}$ & $\begin{array}{c}0.007 \\
(0.022)\end{array}$ & $\begin{array}{c}0.005 \\
(0.023)\end{array}$ \\
\hline incomplete secondary (technical) & & $\begin{array}{l}0.043^{*} \\
(0.024)\end{array}$ & $\begin{array}{c}0.036 \\
(0.024)\end{array}$ & $\begin{array}{c}0.034 \\
(0.024)\end{array}$ & $\begin{array}{c}0.029 \\
(0.024)\end{array}$ \\
\hline complete secondary (technical) & & $\begin{array}{l}0.043^{*} \\
(0.022)\end{array}$ & $\begin{array}{c}0.032 \\
(0.022)\end{array}$ & $\begin{array}{c}0.030 \\
(0.022)\end{array}$ & $\begin{array}{c}0.020 \\
(0.023)\end{array}$ \\
\hline incomplete secondary (vocational) & & $\begin{array}{l}0.042^{*} \\
(0.025)\end{array}$ & $\begin{array}{c}0.031 \\
(0.025)\end{array}$ & $\begin{array}{c}0.029 \\
(0.025)\end{array}$ & $\begin{array}{c}0.021 \\
(0.025)\end{array}$ \\
\hline complete secondary (vocational) & & $\begin{array}{c}0.060^{* *} \\
(0.023)\end{array}$ & $\begin{array}{c}0.046^{* *} \\
(0.023)\end{array}$ & $\begin{array}{l}0.043^{*} \\
(0.023)\end{array}$ & $\begin{array}{c}0.032 \\
(0.024)\end{array}$ \\
\hline incomplete university & & $\begin{array}{c}0.109^{* * *} \\
(0.026)\end{array}$ & $\begin{array}{c}0.092^{* * *} \\
(0.025)\end{array}$ & $\begin{array}{c}0.091^{* * *} \\
(0.025)\end{array}$ & $\begin{array}{c}0.072^{* * *} \\
(0.025)\end{array}$ \\
\hline university degree & & $\begin{array}{c}0.095^{* * *} \\
(0.025)\end{array}$ & $\begin{array}{c}0.076^{* * *} \\
(0.024)\end{array}$ & $\begin{array}{c}0.075^{* * * *} \\
(0.024)\end{array}$ & $\begin{array}{c}0.039 \\
(0.025)\end{array}$ \\
\hline living together & & $\begin{array}{c}0.116^{* * *} \\
(0.017)\end{array}$ & $\begin{array}{c}0.119^{* * *} \\
(0.017)\end{array}$ & $\begin{array}{c}0.120^{* * * *} \\
(0.017)\end{array}$ & $\begin{array}{c}0.118^{* * *} \\
(0.018)\end{array}$ \\
\hline divorced & & $\begin{array}{c}0.138^{* * *} \\
(0.020)\end{array}$ & $\begin{array}{c}0.144^{* * *} \\
(0.020)\end{array}$ & $\begin{array}{c}0.149^{* * * *} \\
(0.020)\end{array}$ & $\begin{array}{c}0.130^{* * *} \\
(0.021)\end{array}$ \\
\hline separated & & $\begin{array}{c}0.109^{* * * *} \\
(0.036)\end{array}$ & $\begin{array}{c}0.115^{* * *} \\
(0.037)\end{array}$ & $\begin{array}{c}0.123^{* * *} \\
(0.037)\end{array}$ & $\begin{array}{c}0.121^{* * *} \\
(0.039)\end{array}$ \\
\hline widowed & & $\begin{array}{c}0.006 \\
(0.021)\end{array}$ & $\begin{array}{c}0.017 \\
(0.020)\end{array}$ & $\begin{array}{c}0.017 \\
(0.021)\end{array}$ & $\begin{array}{c}0.014 \\
(0.022)\end{array}$ \\
\hline single & & $\begin{array}{c}0.182^{* * *} \\
(0.018)\end{array}$ & $\begin{array}{c}0.185^{* * *} \\
(0.018)\end{array}$ & $\begin{array}{c}0.189^{* * *} \\
(0.018)\end{array}$ & $\begin{array}{c}0.185^{* * *} \\
(0.019)\end{array}$ \\
\hline female & & $\begin{array}{c}-0.231^{* * *} \\
(0.013)\end{array}$ & $\begin{array}{c}-0.226^{* * *} \\
(0.013)\end{array}$ & $\begin{array}{c}-0.227^{* * *} \\
(0.013)\end{array}$ & $\begin{array}{c}-0.224^{* * *} \\
(0.014)\end{array}$ \\
\hline age (z-score) & & $\begin{array}{c}-0.261^{* * *} \\
(0.034)\end{array}$ & $\begin{array}{c}-0.244^{* * *} \\
(0.034)\end{array}$ & $\begin{array}{c}-0.236^{* * *} \\
(0.034)\end{array}$ & $\begin{array}{c}-0.199 * * * \\
(0.034)\end{array}$ \\
\hline age square (z-score) & & $\begin{array}{c}0.103^{* * *} \\
(0.031)\end{array}$ & $\begin{array}{c}0.101^{* * *} \\
(0.031)\end{array}$ & $\begin{array}{c}0.092^{* * *} \\
(0.030)\end{array}$ & $\begin{array}{c}0.056^{*} \\
(0.030)\end{array}$ \\
\hline state of health & & & $\begin{array}{c}-0.067^{* * *} \\
(0.007)\end{array}$ & $\begin{array}{c}-0.059^{* * *} \\
(0.007)\end{array}$ & $\begin{array}{c}-0.055^{* * *} \\
(0.007)\end{array}$ \\
\hline life satisfaction & & & & $\begin{array}{c}0.010^{* * *} \\
(0.003)\end{array}$ & $\begin{array}{c}0.009^{* * *} \\
(0.003)\end{array}$ \\
\hline Upper class & & & & & $\begin{array}{c}0.232^{* * *} \\
(0.040)\end{array}$ \\
\hline Upper middle class & & & & & $\begin{array}{c}0.147^{* * *} \\
(0.015)\end{array}$ \\
\hline Lower middle class & & & & & $\begin{array}{c}0.079^{* * *} \\
(0.011)\end{array}$ \\
\hline Constant & $\begin{array}{c}0.003 \\
(0.035) \\
\end{array}$ & $\begin{array}{c}-0.003 \\
(0.037) \\
\end{array}$ & $\begin{array}{c}0.145^{* * *} \\
(0.039) \\
\end{array}$ & $\begin{array}{c}0.059 \\
(0.043) \\
\end{array}$ & $\begin{array}{c}0.017 \\
(0.046) \\
\end{array}$ \\
\hline Observations & 105,442 & 97,143 & 96,840 & 96,175 & 88,458 \\
\hline Countries & 78 & 78 & 78 & 78 & 74 \\
\hline log likelihood & -156592.32 & -141231.97 & -140641.53 & -139681.64 & -127831.73 \\
\hline
\end{tabular}

Robust, heteroscedasticity-resistant standard errors are reported in parentheses. Stars signal significance at the following levels: ${ }^{*} p<0.10,{ }^{* *} p<0.05$, ${ }^{* * *} p<0.01$. Multilevel OLS regressions are used throughout.

All effects are stable when using multilevel ordered logit regressions instead - see online appendix.

satisfaction and ranging from 1 ('dissatisfied with my life') to 10 ('fully satisfied with my life'). This question is meant to control for optimism in the response to qualitative scales. ${ }^{15}$ Inserting this control, however, does not significantly impact the correlation

\footnotetext{
${ }^{15}$ In particular, optimistic people may overestimate their position in the income distribution, while at the same time indicating overly high levels of risk-tolerance. If so, one might observe a correlation between income and risk-tolerance that is spurious. To the extent that the life satisfaction question captures such optimism, it will serve to purify the correlation between income and risk-tolerance we observe in the regression.
} 
between risk-tolerance and income.

Finally, regression $\mathrm{V}$ provides a stability test by investigating social class as a substitute for the income measure. We enter three separate dummies for whether a respondent belongs to the 'upper class', the 'upper middle class', or the 'lower middle class', which are measured relative to 'working class' and 'lower class'. We lump the latter two together in the analysis since in some countries very few respondents have indicated to belong to the 'lower class'. All three dummy variables show the expected positive effect, indicating higher levels of risk-tolerance for higher classes. The effect can be seen to be larger the higher the class, so that respondents belonging to the upper middle class are not only more risk-tolerant than respondents from the working and lower classes, but also than respondents from the lower middle class. Equivalently, respondents from the upper class are more risk-tolerant than respondents from any of the middle classes, as well as the lower classes.

\subsection{A risk-income paradox}

We now move on to juxtaposing the effects of personal income with those of GDP per capita in one and the same regression. Presenting empirical evidence on the paradox constitutes an original contribution of our paper. Other than the results presented above, the paradox also constitutes an original prediction of the two models, which is a priori far from obvious, and can thus serve as a first test of their validity. It is interesting that both models predict this paradox, although based on different reasons (see discussions above surrounding predictions GM1 and GM2, and DZ1 and DZ4 for the details).

Figure 3 shows the basic correlation of aggregate risk-tolerance with GDP per capita. The GDP data are measured in purchasing power parity $(P P P)$ and corrected for oil rents (all correlations shown are stable to abandoning this adjustment). Risk-tolerance decreases in GDP $(r=-0.337, p=0.002)$, in accordance with prediction GM2 and DZ4. Notice also that since the support for the risk-tolerance question is the same by construction-answers range from 1 to 6 - any shift in aggregate risk-tolerance must reflect a shift in the proportion of different types (see Online Appendix for an additional analysis of this point). Clearly, this only shows that there exists a correlation with GDP, not that GDP is the driving factor or main correlate of risk-tolerance - this issue will be discussed extensively below. A further caveat is that we have plotted only average 
risk-tolerance by country. This bypasses the issue that sample composition may differ by country - and potentially systematically so - for instance because developing countries typically have younger populations, and we found risk-tolerance to decline with age.

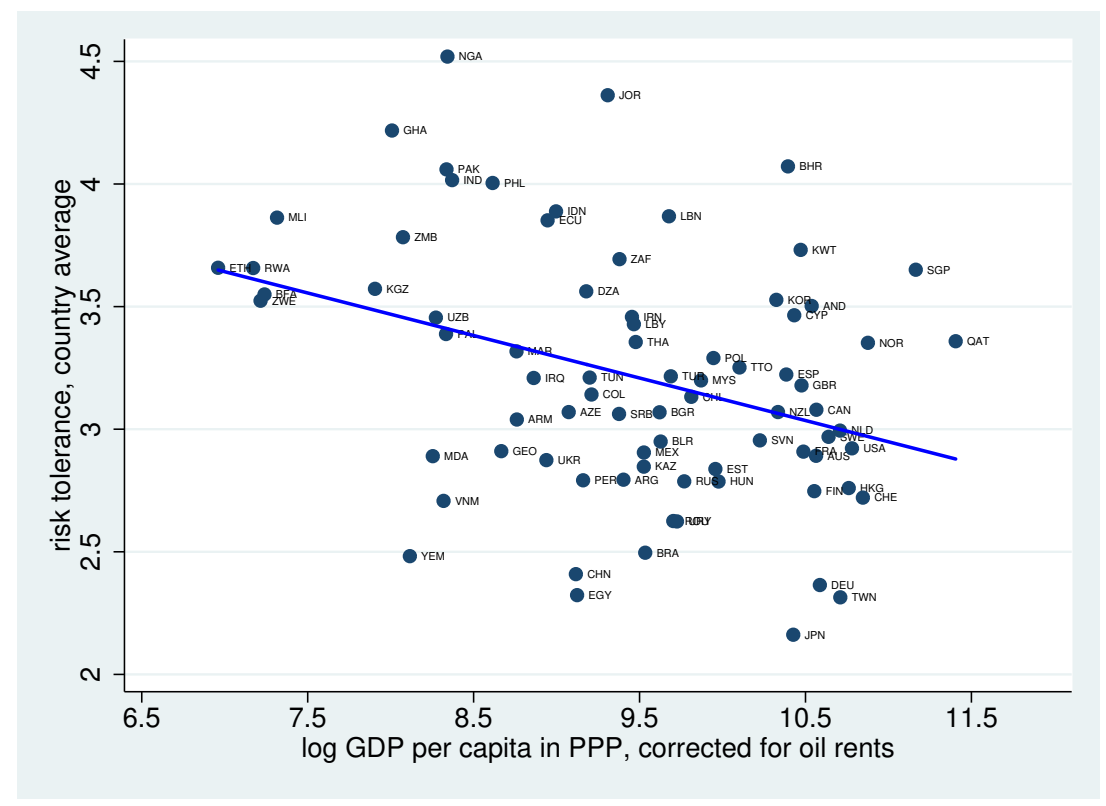

Figure 3: Correlation between average risk aversion and GDP per capita

We now move on to a more formal analysis of the between-country relationships. While the different macroeconomic variables may well be causally related (Keefer and Knack, 1997; Levine, 1998; Gallup, Sachs and Mellinger, 1999; Ashraf and Galor, 2013), we remain explicitly agnostic as to the relationship between the different macroeconomic variables, and add them purely as controls to guard against bias deriving from omitted variables. Table 4 shows regressions of risk-tolerance on such macroeconomic variables. Regression I shows the effects of our main between-country predictor, GDP per capita, and juxtaposes it with the effect of individual income. GDP per capita shows a strongly negative effect on risk-tolerance - richer countries are on average less risk-tolerant. This is consistent with predictions GM2 and DZ4. Personal income shows a positive correlation with risk-tolerance, thus going exactly in the opposite direction of the macro relation - this completes the paradox.

Regression II adds genetic distance from Ethiopia as an additional explanatory variable (Ashraf and Galor, 2013). Genetic distance itself shows a marginally significant negative effect on risk-tolerance. That is, risk-tolerance decreases in genetic distance from Ethiopia, holding GDP constant (adding the square of genetic distance does not 
Table 4: Macroeconomic correlates of risk-tolerance

\begin{tabular}{lccccc}
\hline dep. var: risk-tolerance & $\mathrm{I}$ & $\mathrm{II}$ & $\mathrm{III}$ & $\mathrm{IV}$ & $\mathrm{V}$ \\
\hline log GDP p.c. & $-0.112^{* * *}$ & $-0.094^{* * *}$ & $-0.084^{* * *}$ & $-0.099^{* * *}$ & $-0.081^{* *}$ \\
& $(0.028)$ & $(0.032)$ & $(0.030)$ & $(0.033)$ & $(0.035)$ \\
income (z-score) & $0.069^{* * *}$ & $0.065^{* * *}$ & $0.064^{* * *}$ & $0.064^{* * *}$ & $0.043^{* * *}$ \\
& $(0.009)$ & $(0.009)$ & $(0.009)$ & $(0.004)$ & $(0.005)$ \\
Gini coeff. & & 0.004 & -0.001 & -0.000 & -0.001 \\
& & $(0.002)$ & $(0.004)$ & $(0.001)$ & $(0.001)$ \\
Genetic distance to Ethiopia & & $-0.024^{* *}$ & -0.007 & $-0.012^{* * *}$ & $-0.009^{* *}$ \\
& & $(0.011)$ & $(0.011)$ & $(0.003)$ & $(0.004)$ \\
Institutional controls & & & $\checkmark$ & $\checkmark$ & $\checkmark$ \\
Geographic controls & & & & $\checkmark$ & $\checkmark$ \\
Individual controls & & & & & $\checkmark$ \\
Constant & $1.059^{* * *}$ & $1.023^{* * *}$ & $1.056^{* * *}$ & $1.187^{* * *}$ & $0.967^{* * *}$ \\
& $(0.272)$ & $(0.316)$ & $(0.324)$ & $(0.302)$ & $(0.319)$ \\
\hline Observations & 101090 & 97679 & 96687 & 96687 & 89129 \\
Countries & 78 & 72 & 71 & 71 & 71 \\
log-likelihood & -155167.6 & -143642.46 & -141735.78 & -141734.26 & -128142.5 \\
\hline
\end{tabular}

Robust, heteroscedasticity-resistant standard errors are reported in parentheses. These are clusterrobust standard errors suitable for the multilevel structure (Zeger et al., 1988). Stars signal significance at the following levels: ${ }^{*} p<0.10,{ }^{* *} p<0.05$, ${ }^{* * *} p<0.01$. Multilevel OLS regression is used throughout. OLS is the recommended methodology for outcome variables with 6 or more categories, since it produces more stable results when random slopes are included (Snijders and Bosker, 2012, p. 311). All results are stable to using ordered logistic regression instead - see online appendix. Institutional controls include legal origin dummies, and a measure of overall institutional quality (democracy). Geographic controls include absolute latitude and continental fixed effects. Demographic factors include the individual controls used above.

yield additional insights). This effect is in agreement with the one reported by Becker, Dohmen, Enke and Falk (2015).

Subsequent regressions serve the purpose of probing the stability of our main results. Regression III further adds institutional variables, and in particular democracy (a variable capturing the overall institutional quality on a scale from from 0-10; see Ashraf and Galor, 2013) and legal origin dummies (La Porta, López-de Silanes, Shleifer and Vishny, 1998). The effect of GDP remains highly significant, while genetic distance loses its significance. Regression IV adds geographical controls. These consist of a measure of absolute distance from the equator, and of an additional cluster at the continent level. The addition of these control variables does not impact the effect of GDP per capita.

Regression V further adds individual-level variables. These are important inasmuch as differing proportions of individual characteristics between countries may influence the macro-economic correlations, a so-called 'compositional effect' (e.g. if risk-tolerance decreases in age and populations are younger in poorer countries, this demographic trend could potentially account for the negative correlation between aggregate risk-tolerance and GDP per capita). Adding variables on age, age squared, sex, educational attainment, 
marital status, and relative personal income does not affect our conclusion in any way. The effect of income can be seen to go in the opposite direction of the one of GDP per capita, thus directly visualizing the risk-income paradox. Overall, this shows that the effect of GDP per capita is stable to a variety of the most common macroeconomic correlates of GDP.

\subsection{Risk-tolerance, the entrepreneurship wage premium, and past growth}

Figure 4 shows the raw correlation between risk-tolerance and the entrepreneurship wage premium (EWP; panel 4(a)), and between risk-tolerance and growth (panel 4(b)). ${ }^{16}$ The EWP is calculated as the mean income of respondents who declare to be self-employed, minus the mean income of respondents who are not self-employed. The simple correlation can be seen to be negative, an effect that is marginally significant $(r=-0.221, p=$ 0.053). This effect in the opposite direction of the one predicted, however, may be driven by the strong correlation of the EWP with GDP per capita $(r=0.461, p<0.001)$, so that multiple regressions may be more informative. Looking at growth, we find a clear positive correlation $(r=0.294, p=0.011)$, which is consistent with prediction DZ3.

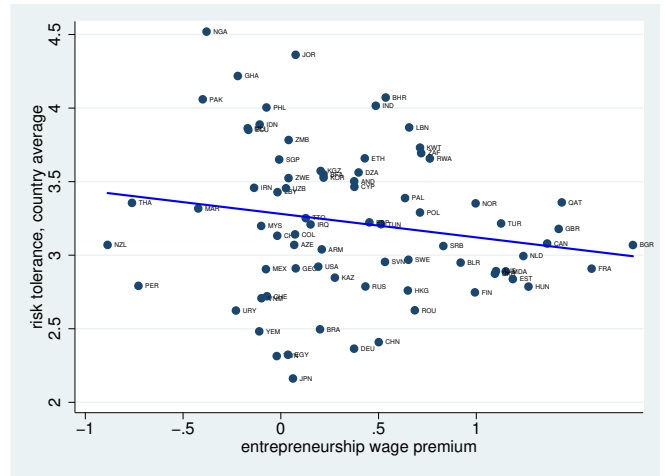

(a) Entrepreneurship wage premium

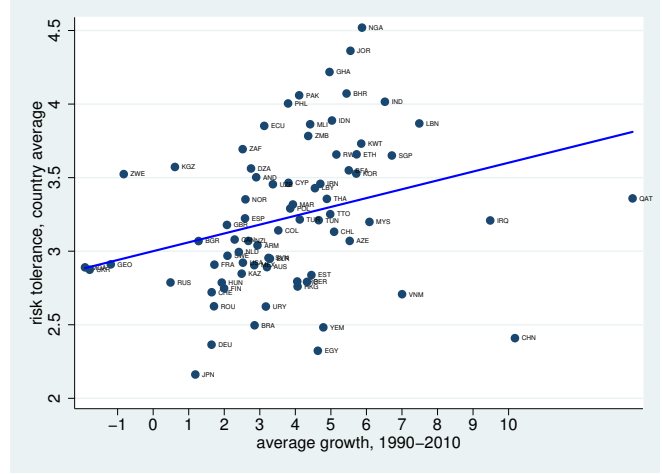

(b) Growth average, 1990-2010

Figure 4: Correlation between average risk-tolerance and EWP and past growth

Table 5 shows the regression results. We only show the newly added EWP and growth variables. The effects of GDP per capita and income are entirely stable to this addition, while the effects of genetic distance to Ethiopia result somewhat attenuated. Regression I shows the effects of the EWP and of average growth per year over the

\footnotetext{
${ }^{16}$ Notice how we take the contemporary EWP and the growth of the previous 20 years to test for the relationships predicted in the model. While risk-tolerance levels are determined by levels of these variables at the time parents educated their children, and thus generally earlier than we observe them, this strategy is legitimate in terms of the theory since the predictions are derived in equilibrium.
} 
last 20 years, controlling only for GDP p.c. and income. The EWP shows no effect, while past growth shows a positive effect consistent with prediction DZ3. The number of countries is reduced to $74 .{ }^{17}$ Regression II adds the Gini coefficient and genetic distance from Ethiopia, which leaves the effects unaltered. Regression III adds institutional controls. Growth no no longer shows an effect, while the EWP now shows a positive effect consistent with prediction DZ2 (significant at 10\%). Adding geographic and individual controls in regressions IV and V makes both effects appear non-significant.

Table 5: Risk-tolerance, EWP, and past growth

\begin{tabular}{lccccc}
\hline dep. var: risk-tolerance & I & II & III & IV & V \\
\hline EWP & -0.011 & -0.016 & $0.081^{*}$ & 0.073 & 0.059 \\
& $(0.046)$ & $(0.045)$ & $(0.042)$ & $(0.050)$ & $(0.047)$ \\
growth past 20 years & $0.035^{* *}$ & $0.036^{* *}$ & 0.016 & 0.008 & 0.003 \\
& $(0.015)$ & $(0.014)$ & $(0.014)$ & $(0.023)$ & $(0.018)$ \\
Income controls & $\checkmark$ & $\checkmark$ & $\checkmark$ & $\checkmark$ & $\checkmark$ \\
Gini and genetic distance & & $\checkmark$ & $\checkmark$ & $\checkmark$ & $\checkmark$ \\
Institutional controls & & & $\checkmark$ & $\checkmark$ & $\checkmark$ \\
Geographic controls & & & & $\checkmark$ & $\checkmark$ \\
Individual controls & & & & & $\checkmark$ \\
Constant & $0.851^{* * *}$ & $0.989^{* * *}$ & $1.312^{* * *}$ & $1.373^{* * *}$ & $1.107^{* * *}$ \\
& $(0.247)$ & $(0.291)$ & $(0.316)$ & $(0.353)$ & $(0.368)$ \\
\hline Observations & 101090 & 97679 & 96687 & 96687 & 89129 \\
Countries & 74 & 71 & 70 & 70 & 70 \\
log-likelihood & -147582.740 & -141711.448 & -139807.351 & -139806.697 & -126321.197 \\
\hline Robist hes
\end{tabular}

Robust, heteroscedasticity-resistant standard errors are reported in parentheses. These are clusterrobust standard errors suitable for the multilevel structure (Zeger et al., 1988). Stars signal significance at the following levels: ${ }^{*} p<0.10,{ }^{* *} p<0.05,{ }^{* * *} p<0.01$. Multilevel OLS regression is used throughout. OLS is the recommended methodology for outcome variables with 6 or more categories, since it produces more stable results when random slopes are included (Snijders and Bosker, 2012, p. 311). All results are stable to using ordered logistic regression instead - see online appendix. EWP stands for 'entrepreneurial wage premium'. Institutional controls include legal origin dummies, and a measure of overall institutional quality (democracy). Geographic controls include absolute latitude and continental fixed effects. Demographic factors include the individual controls used above.

The evidence for the DZ hypotheses thus appears at best mixed from our data. Nor does this conclusion change if we use directly a proxy of the riskiness of the environment, such as death rates, instead of GDP per capita. ${ }^{18}$ While we find some evidence for both predictions in some of the correlations, these effects appear to be rather weak, as well as sensitive to what controls are included in the regression. We do, however, suggest to interpret these effects with caution, given potential issues with the data we use. For

\footnotetext{
${ }^{17}$ This reflects the absence of growth data for some countries and territories in the World Bank tables (Palestine, Taiwan, and Serbia and Montenegro), as well as the absence of wage premium data for Argentina.

${ }^{18}$ This is not surprising. Taking an index of deaths per year out of 1000 people published by the World Bank, we find that the latter has a correlation of 0.89 with GDP per capita.
} 
instance, the entrepreneurial wage premium may be a rather noisy measure, since what constitutes 'entrepreneurship' may be interpreted very differently across countries. It is furthermore unclear whether he particular measure of riskiness of the environment given by death rates is the correct one to use as a control. Future research will have to probe these points in more depth.

\subsection{Risk-tolerance and fertility}

A specific prediction emerging from the model by Galor and Michalopoulos (2012) that is not shared with the models of Doepke and Zilibotti (2014) is prediction GM3 - the dependence of the correlation between risk-tolerance and fertility on the level of development. In particular, the prediction is that risk-tolerance will be strongly negatively correlated with number of children in developed countries, while this correlation is expected to be positive in countries that find themselves in a Malthusian equilibrium. Arguably, however, no country nowadays can be described as finding itself in a Malthusian steady state. Indeed, it has been argued that virtually all African countries had started the fertility transition by the late 1980s (Cohen, 1998). Using more reliable data, Garenne and Joseph (2002) dated the incept of the fertility transition even earlier, showing that the fertility transition had started in most sub-Saharan African countries by the mid 1970s at least in the cities, with the countryside typically lagging behind by a decade or more. This leads to a weaker prediction of a negative interaction effect of risk-tolerance and GDP per capita on the number of children.

Figure 5 plots the country-level correlations between risk-tolerance and the number of children against log GDP per capita. We find a strong negative correlation $(r=-0.426, p<0.001, N=76) .{ }^{19}$ This is in agreement with prediction GM3. Most rich countries are characterized by significantly negative correlations between risk-tolerance and fertility, while in poor countries this negative correlation is much weaker, and oftentimes not significant (e.g., in Rwanda, Mali, Ghana, the Philippines, and India). Below we will go further by investigating correlations at the regional level, based on the observation that the fertility transition may have happened later in rural regions, so that we may expect to still be able to observe positive correlations there. First, however, we analyse the country-level effect formally, to probe its stability.

\footnotetext{
${ }^{19}$ The number of countries is reduced to 76 inasmuch as the question about number of children has no entries for Hong Kong and the USA.
} 


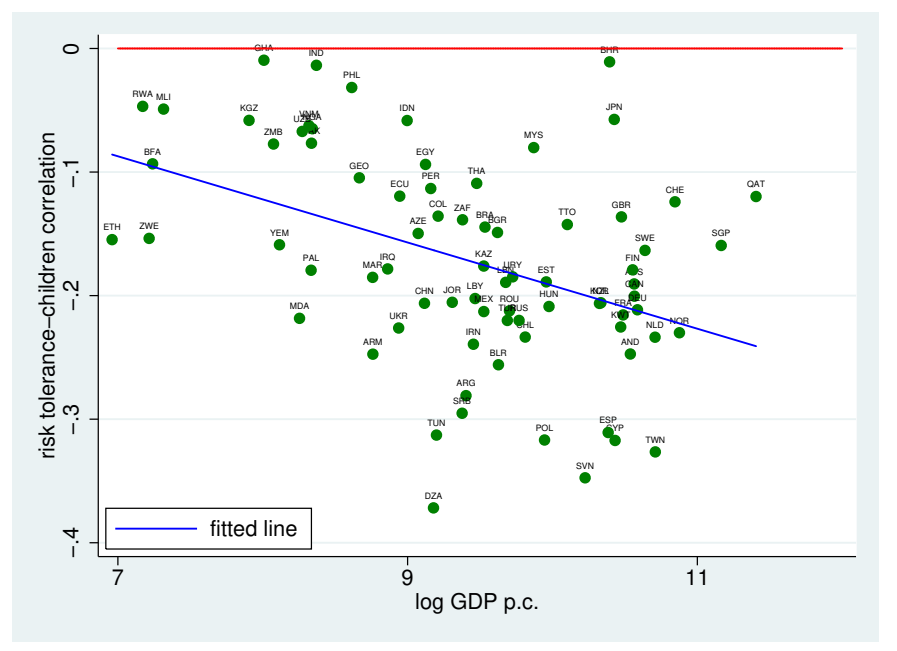

Figure 5: risk-tolerance-children correlation by GDP level

Table 6 shows regressions of the number of children a family has on risk-tolerance and several other variables. Regression I establishes the most basic relationships with risk-tolerance and GDP per capita. The regression shows that the number of children declines in GDP per capita, and that the average correlation between risk-tolerance and number of children is negative. Regression II introduces the main element of interest in our analysis - the interaction between risk-tolerance and GDP per capita. We observe two effects. One, the pure effect of risk-tolerance, capturing the effect of risk-tolerance when the interaction term with GDP is 0 , is now positive. Two, the interaction term itself is negative and highly significant, indicating that the correlation between number of children and risk-tolerance decreases in GDP per capita. This interaction term further takes up all of the effect of GDP, so that the pure effect of GDP per capita is no longer significant. In other words, the decrease in the number of children as GDP rises is fully accounted for by GDP's interaction with risk-tolerance. ${ }^{20}$

The subsequent regressions serve the purpose of testing the stability of these effects to various macro- and micro-economic controls. Regression III adds a number of macroeconomic variables, including genetic distance from Addis Ababa and the usual institutional variables. Regression IV further adds absolute latitude, and continental clusters. Finally, regression $\mathrm{V}$ adds a number of controls at the individual level. The effects of risk-tolerance and its interaction with GDP per capita remain stable through-

\footnotetext{
${ }^{20}$ Technically, the pure effect of GDP p.c. captures the effect of GDP on the number of children for the mean level of risk-tolerance, since the latter is entered into the interaction as a z-score. That is, for an average level of risk-tolerance, GDP per capita per se has no predictive value for between-country differenes in fertility once cross-country variations in risk-tolerance are taken into account.
} 
Table 6: Determinants of fertility

\begin{tabular}{lccccc}
\hline dep. var: nr. of children & I & II & III & IV & V \\
\hline risk-tolerance (z-score) & $-0.292^{* * *}$ & $0.184^{* * *}$ & $0.239^{* * *}$ & $0.241^{* * *}$ & $0.256^{* * *}$ \\
& $(0.006)$ & $(0.054)$ & $(0.057)$ & $(0.057)$ & $(0.057)$ \\
log GDP p.c. & $-0.191^{* * *}$ & -0.083 & -0.028 & -0.037 & 0.053 \\
& $(0.051)$ & $(0.052)$ & $(0.052)$ & $(0.058)$ & $(0.068)$ \\
risk-tolerance*GDP p.c. & & $-0.032^{* * *}$ & $-0.035^{* * *}$ & $-0.035^{* * *}$ & $-0.032^{* * *}$ \\
& & $(0.004)$ & $(0.004)$ & $(0.004)$ & $(0.004)$ \\
institutional and genetic variables & & & $\checkmark$ & $\checkmark$ & $\checkmark$ \\
geographical variables & & & & $\checkmark$ & $\checkmark$ \\
education level and income & & & & & $\checkmark$ \\
Constant & $3.715^{* * *}$ & $3.665^{* * *}$ & $3.555^{* * *}$ & $3.781^{* * *}$ & $3.682^{* * *}$ \\
& $(0.481)$ & $(0.483)$ & $(0.451)$ & $(0.507)$ & $(0.643)$ \\
\hline Observations & 102531 & 102531 & 95784 & 95784 & 88672 \\
Countries & 76 & 76 & 70 & 70 & 70 \\
log-likelihood & -204965.003 & -204925.02 & -191535.02 & -191533.50 & -169454.60 \\
\hline
\end{tabular}

Robust, heteroscedasticity-resistant standard errors are reported in parentheses. Starts signal significance at the following levels: ${ }^{*} p<0.10,{ }^{*} p<0.05$, *** $p<0.01$. Multilevel OLS regression is used throughout, with errors clustered according to the appropriate units of analysis (individuals, countries).

out. The pure effect of risk tolerance suggests a positive effect on fertility when log GDP per capita is held constant at zero, which is not a meaningful quantity. Taking the results from regression $\mathrm{V}$, we can calculate that the effect of risk-tolerance on fertility changes from positive to negative at a level of log GDP per capita equal to 7.98. Only six countries-Burkina Faso, Ethiopia, Kyrgyzstan, Mali, Rwanda, and Zimbabwe - fall below that level in our data. The evidence for positive effects of risk-tolerance on fertility at the country level is thus rather weak.

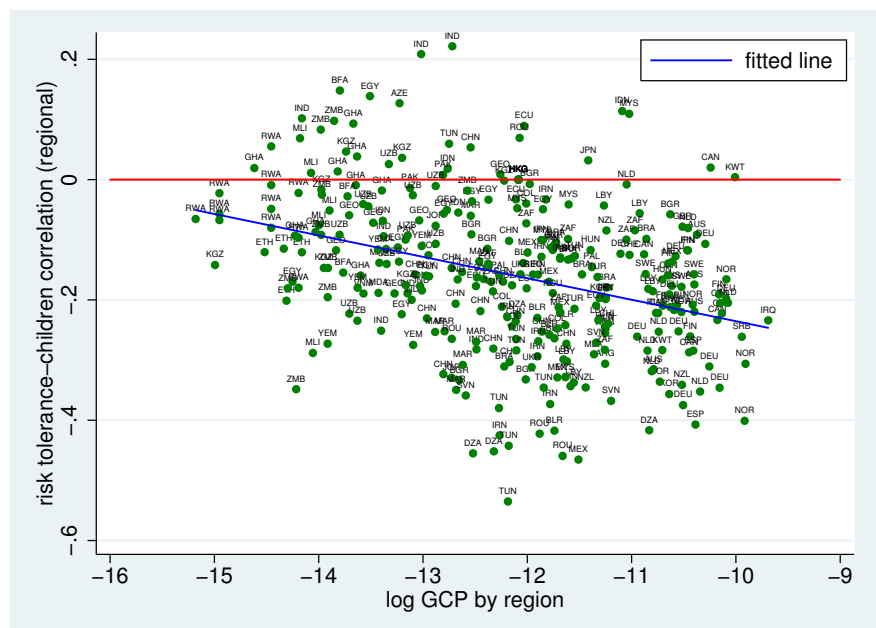

Figure 6: risk-tolerance-fertility correlation at regional level plotted against national log GDP p.c.

The absence of positive correlations between risk-tolerance and the number of children at the country level may indicate that contemporary developing countries are already too far past the fertility transition to detect this effect. It may, however, be possible 
to still find such positive correlations at the sub-national level, given how rural regions typically lag behind more urbanized regions in terms of the fertility transition. Figure 6 shows the correlation of risk-tolerance and number of children, plotted against a measure of income per capita at the regional level. ${ }^{21}$ We restrict ourselves to regions for which we have at least 60 observations, in order to avoid outliers in the correlation deriving from small sample sizes (the results are stable to using smaller or larger cutoff points). The correlation is negative as expected and highly significant $(r=-0.341, p<0.001, N=$ 312). We also observe a number of positive correlations especially in poor and middle income countries. This supports prediction GM3 in its stronger form.

\section{Conclusion}

We set out to test the predictions of two growth models that describe risk-tolerance as endogenously determined by growth processes. We found considerable support for the main mechanism underlying the models, that risk-tolerance acts as a determinant of entrepreneurship. More originally, we found evidence of a risk-income paradox. The latter consists of a positive correlation between risk-tolerance and income within countries, in combination with a negative correlation between aggregate risk-tolerance and GDP per capita between countries. The latter may seem surprising in light of a view of developing countries as being extremely risk averse, which prevailed until very recently (Haushofer and Fehr, 2014). Nevertheless, this result is highly consistent with previous evidence based on students (Rieger et al., 2014; Vieider et al., 2015). It is also in agreement with the predictions derived from the model of Galor and Michalopoulos (2012), and the general spirit of Doepke and Zilibotti (2014).

A central element in the model of Doepke and Zilibotti (2014) is that risk-tolerance is instilled by parents into their children to prepare them for the environment they will face as adults. In this sense, riskiness of the environment may be one of the factors inducing parents to instill risk-tolerance into their children. At first sight, this interpretation of their model appears to present parallels to theories from biology adopted into psychology. According to so-called life-history theory, high environmental uncertainty about the

\footnotetext{
${ }^{21}$ We assembled the income per capita data at the regional level from the gross-cell-product $(G C P)$ data assembled and discussed by Nordhaus (2006). The graph excludes a few extreme outliers on the GCP scale, generally found in petrolium-producing regions. The online appendix provides details on the assembly of the GCP data, and a stability analysis.
} 
future induces people to take large amounts of risk in order to maximize their immediate payoffs (Hill, Ross and Low, 1997). In particular, Wilson and Daly (1997) showed a number of correlations between the average life expectancy in Chicago neighborhoods and risk-taking behaviors such as homicide rates, age at first child, and number of children. Notice, however, how life history theory postulates that individuals themselves exhibit a reaction to the riskiness of the environment. This is different from a setup where parents socialize children, and indeed it results in predictions of differential riskiness by neighbourhoods rather than whole countries. These predictions do not appear to be borne out by our data, given the positive correlation between risk-tolerance and income, and thus seem generally in contradiction to the within-country effects we find.

The most important differences between the models of Galor and Michalopoulos (2012) and Doepke and Zilibotti (2014) concern the transmission of risk-tolerance. In particular, Galor and Michalopoulos (2012) take no explicit stand on the mechanism through which risk-tolerance is transmitted. Some form of vertical transmission is, however, central to their model, given the role played by fertility. Fertility plays no explicit role in the model of Doepke and Zilibotti (2014), who on the other hand put the emphasis on parents' decision to instill beneficial levels of risk-tolerance into their children. Testing the underlying mechanisms, we did indeed found strong support for the fertility channel postulated by Galor and Michalopoulos (2012), while we did not find any strong support for the mechanisms modeled by Doepke and Zilibotti (2014).

The empirical evidence on how intergenerational transmission works is still limited. There is clear evidence that the risk-tolerance of parents and children is correlated (Kimball et al., 2009; Dohmen et al., 2012). While Cesarini, Dawes, Johannesson, Lichtenstein and Wallace (2009) and Zhong, Chew, Set, Zhang, Xue, Sham, Ebstein and Israel (2009) have shown that some of the intergenerational correlation in risk-tolerance appears to have genetic origins, the two studies came up with radically different estimates about the strength of this effect, and a genetic component does not exclude cultural transmission. Notwithstanding the careful examination of intergenerational correlations carried out by Dohmen et al. (2012), the evidence for purely cultural mechanisms remains weak. There are, however, other indications in the empirical literature that risk-tolerance may be shaped by the economic environment. Malmendier and Nagel (2011) showed that macroeconomic events during a person's youth may have lasting effects on their risktolerance. Booth and Nolen (2012) found systematic differences in the risk-tolerance 
of girls from single sex schools and mixed sex schools, which are suggestive of horizontal social transmission of risk-tolerance. Bacon, Conte and Moffatt (2014) showed that assimilation plays a role in explaining the correlation in the risk-tolerance of couples. More work quantifying the relative strength of different transmission mechanisms is clearly needed in order to calibrate this aspect of the models. 


\section{References}

Andersen, Steffen, Glenn W. Harrison, Morten Igel Lau, and E. Elisabet Rutström (2010) 'Preference heterogeneity in experiments: Comparing the field and laboratory.' Journal of Economic Behavior \&3 Organization 73(2), 209-224

Andersson, Ola, Jean-Robert Tyran, Erik Wengström, and Håkan J. Holm (2016) 'Risk Aversion Relates to Cognitive Ability: Preferences or Noise?' Journal of the European Economic Association 14(5), 1129-1154

Ashraf, Quamrul, and Oded Galor (2013) "The "Out of Africa" Hypothesis, Human Genetic Diversity, and Comparative Economic Development.' The American Economic Review 103(1), 1-46

Ashraf, Quamrul H, and Oded Galor (2018) 'The macrogenoeconomics of comparative development.' Journal of Economic Literature 56(3), 1119-55

Bacon, Philomena M., Anna Conte, and Peter G. Moffatt (2014) 'Assortative mating on risk attitude.' Theory and Decision 77(3), 389-401

Barro, Robert J. (1991) 'Economic Growth in a Cross-Section of Countries.' Quarterly Journal of Economics

Becker, Anke, Thomas Dohmen, Benjamin Enke, and Armin Falk (2015) 'The Ancient Origins of the Cross-Country Heterogeneity in Risk Preferences.' Working Paper

Becker, Gary S. (1960) 'An Economic Analysis of Fertility.' In 'Demographic and Economic Change in Developed Countries' (209: Princeton University Press) pp. 209-240

Becker, Gary S., Kevin M. Murphy, and Robert Tamura (1990) 'Human Capital, Fertility, and Economic Growth.' Journal of Political Economy 98(5), S12-S37

Benjamin, Daniel J., Sebastian A. Brown, and Jesse M. Shapiro (2013) 'Who Is 'Behavioral'? Cognitive Ability and Anomalous Preferences.' Journal of the European Economic Association 11(6), 1231-1255

Binswanger, Hans P. (1980) 'Attitudes toward Risk: Experimental Measurement in Rural India.' American Journal of Agricultural Economics 62(3), 395-407

Bisin, Alberto, and Thierry Verdier (2001) 'The Economics of Cultural Transmission and the Dynamics of Preferences.' Journal of Economic Theory 97(2), 298-319

Bonin, Holger, Thomas Dohmen, Armin Falk, David Huffmann, and Uwe Sunde (2007) 'Cross-sectional earnings risk and occupational sorting: The role of risk attitudes.' Labour Economics 14(6), 926-937 
Booij, Adam S., Bernard M. S. van Praag, and Gijs van de Kuilen (2010) 'A parametric analysis of prospect theory's functionals for the general population.' Theory and Decision 68(1-2), 115-148

Booth, Alison L., and Patrick Nolen (2012) 'Gender differences in risk behaviour: does nurture matter?' The Economic Journal 122(558), F56-F78

Bowles, Samuel (1998) 'Endogenous preferences: The cultural consequences of markets and other economic institutions.' Journal of Economic Literature 36(1), 75-111

Cardenas, Juan Camilo, and Jeffrey Carpenter (2013) 'Risk attitudes and economic wellbeing in Latin America.' Journal of Development Economics 103, 52-61

Cesarini, David, Christopher T. Dawes, Magnus Johannesson, Paul Lichtenstein, and Björn Wallace (2009) 'Genetic Variation in Preferences for Giving and Risk Taking.' Quarterly Journal of Economics 124(2), 809-842

Charles, Kerwin Kofi, and Erik Hurst (2003) 'The Correlation of Wealth Across Generations.' Journal of Political Economy 111(6), 1155-1182

Clark, Gregory (2007) A Farewell to Alms: A Brief Economic History of the World (Princeton and Oxford: Princeton University Press)

Clark, Gregory, and Gillian Hamilton (2006) 'Survival of the Richest: The Malthusian Mechanism in Pre-Industrial England.' Journal of Economic History 66(3), 707-736

Cohen, Barney (1998) 'The emerging fertility transition in sub-Saharan Africa.' World Development 26(8), 1431-1461

Cramer, J. S., Joop Hartog, N. Jonker, and C. M. van Praag (2002) 'Low Risk Aversion Encourages the Choices for Entrepreneurship: An Empirical Test of a Truism.' Journal of Economic Behavior \& Organization 48, 29-36

Croson, Rachel, and Uri Gneezy (2009) 'Gender Differences in Preferences.' Journal of Economic Literature 47(2), 1-27

di Falco, Salvatore, and Ferdinand M. Vieider (2018) 'Assimilation in the risk preferences of spouses.' Economic Inquiry 56(3), 1809-1816

Doepke, Matthias, and Fabrizio Zilibotti (2008) 'Occupational choice and the spirit of capitalism.' Quarterly Journal of Economics 123(2), 747-793

Doepke, Matthias, and Fabrizio Zilibotti (2014) 'Culture, Entrepreneurship, and Growth.' In 'Handbook of Economic Growth,' vol. 2

Doepke, Matthias, and Fabrizio Zilibotti (2017) 'Parenting with style: Altruism and 
paternalism in intergenerational preference transmission.' Econometrica 85(5), 13311371

Dohmen, Thomas, Armin Falk, David Huffman, and Uwe Sunde (2010) 'Are Risk Aversion and Impatience Related to Cognitive Ability?' American Economic Review $100,1238-1260$

_ (2012) 'The Intergenerational Transmission of Risk and Trust Attitudes.' Review of Economic Studies 70(2), 645-677

Dohmen, Thomas, Armin Falk, David Huffman, Uwe Sunde, Jürgen Schupp, and Gert G. Wagner (2011) 'Individual Risk Attitudes: Measurement, Determinants, and Behavioral Consequences.' Journal of the European Economic Association 9(3), 522-550

Falk, Armin, Anke Becker, Thomas Dohmen, Benjamin Enke, David Huffman, and Uwe Sunde (2018) 'Global evidence on economic preferences.' The Quarterly Journal of Economics, forthcoming

Fehr-Duda, Helga, and Thomas Epper (2012) 'Probability and Risk: Foundations and Economic Implications of Probability-Dependent Risk Preferences.' Annual Review of Economics 4(1), 567-593

Galizzi, Matteo M., Sara R. Machado, and Raffaele Miniaci (2016) 'Temporal Stability, Cross-Validity, and External Validity of Risk Preferences Measures: Experimental Evidence from a UK Representative Sample.' SSRN Scholarly Paper ID 2822613, Social Science Research Network, Rochester, NY, August

Gallup, John Luke, Jeffrey D. Sachs, and Andrew D. Mellinger (1999) 'Geography and Economic Development.' International Regional Science Review 22(2), 179-232

Galor, Oded, and David N. Weil (2000) 'Population, Technology, and Growth: From Malthusian Stagnation to the Demographic Transition and beyond.' American Economic Review 90(4), 806-828

Galor, Oded, and Marc Klemp (2019) 'Human genealogy reveals a selective advantage to moderate fecundity.' Nature Ecology \& Evolution 3, 853-857

Galor, Oded, and Omer Moav (2002) 'Natural Selection and the Origin of Economic Growth.' Quarterly Journal of Economics 117(4), 1133-1191

Galor, Oded, and Ömer Özak (2016) 'The agricultural origins of time preference.' American Economic Review 106(10), 3064-3103

Galor, Oded, and Stelios Michalopoulos (2012) 'Evolution and the Growth Process: 
Natural Selection of Entrepreneurial Traits.' Journal of Economic Theory 147(2), 759780

Galor, Oded, and Viacheslav Savitskiy (2018) 'Climatic Roots of Loss Aversion.' Technical Report

Garenne, Michel, and Veronique Joseph (2002) 'The Timing of the Fertility Transition in Sub-Saharan Africa.' World Development 30(10), 1835-1843

Gloede, Oliver, Lukas Menkhoff, and Hermann Waibel (2015) 'Shocks, Individual Risk Attitude, and Vulnerability to Poverty among Rural Households in Thailand and Vietnam.' World Development 71, 54-78

Goodman, Anna, Ilona Koupil, and David W. Lawson (2012) 'Low fertility increases descendant socioeconomic position but reduces long-term fitness in a modern postindustrial society.' Proceedings of the Royal Society $B$

Görlitz, Katja, and Marcus Tamm (2015) 'Parenthood and Risk Preferences.' SSRN Scholarly Paper ID 2618442, Social Science Research Network, Rochester, NY, April

Hardeweg, Bernd, Lukas Menkhoff, and Hermann Waibel (2013) 'Experimentally Validated Survey Evidence on Individual Risk Attitudes in Rural Thailand.' Economic Development and Cultural Change 61(4), 859-888

Haushofer, Johannes, and Ernst Fehr (2014) 'On the psychology of poverty.' Science 344(6186), 862-867

Hill, Elizabeth M, Lisa Thomson Ross, and Bobbi S Low (1997) 'The role of future unpredictability in human risk-taking.' Human Nature 8(4), 287

Hopland, Arnt O, Egil Matsen, and Bjarne Strøm (2016) 'Income and choice under risk.' Journal of Behavioral and Experimental Finance 12, 55-64

Keefer, Philip, and Stephen Knack (1997) 'Why Don't Poor Countries Catch up? a Cross-National Test of an Institutional Explanation.' Economic Inquiry 35(3), 590602

Kimball, Miles S., Claudia R. Sahm, and Matthew D. Shapiro (2009) 'Risk Preferences in the PSID: Individual Imputations and Family Covariation.' American Economic Review, Papers and Proceedings 99(2), 363-368

Klasing, Mariko J. (2014) 'Cultural change, risk-taking behavior and implications for economic development.' Journal of Development Economics 110, 158-169

La Porta, Rafael, Florencio López-de Silanes, Andrei Shleifer, and Robert Vishny (1998) 
'Law and Finance.' Journal of Political Economy 106(6), 1113-1155

Levine, Ross (1998) 'The Legal Environment, Banks, and Long-Run Economic Growth.' Journal of Money, Credit and Banking 30(3), 596-613

L'Haridon, Olivier, and Ferdinand M. Vieider (2019) 'All over the map: A worldwide comparison of risk preferences.' Quantitative Economics 10, 185?-215

Lönnqvist, Jan-Erik, Markku Verkasalo, Gari Walkowitz, and Philipp C. Wichardt (2015) 'Measuring individual risk attitudes in the lab: Task or ask? An empirical comparison.' Journal of Economic Behavior $\&$ Organization 119, 254-266

Malmendier, Ulrike, and Stefan Nagel (2011) 'Depression Babies: Do Macroeconomic Experiences Affect Risk Taking?*' The Quarterly Journal of Economics 126(1), 373416

Moulton, Brent R. (1986) 'Random group effects and the precision of regression estimates.' Journal of Econometrics 32(3), 385-397

Nordhaus, William D. (2006) 'Geography and macroeconomics: New data and new findings.' Proceedings of the National Academy of Sciences of the United States of America 103(10), 3510-3517

Noussair, Charles N., Stefan Trautmann, and Gijs van de Kuilen (2014) 'Higher Order Risk Attitudes, Demographics, and Financial Decisions.' Review of Economic Studies $21(1), 325-355$

Rieger, Marc Oliver, Mei Wang, and Thorsten Hens (2014) 'Risk Preferences Around the World.' Management Science 61(3), 637 - 648

Robinson, W. (1950) 'Ecological correlations and the behavior of individuals.' American Sociological Review 15, 351-357

Sala-i Martin, Xavier X. (1996) 'The Classical Approach to Convergence Analysis.' Economic Journal 106(437), 1019-36

Schmidt, Lucie (2008) 'Risk preferences and the timing of marriage and childbearing.' Demography 45(2), 439-460

Shaw, Kathryn L. (1996) 'An empirical analysis of risk aversion and income growth.' Journal of Labor Economics 14(4), 626-653

Snijders, Tom A. B., and Roel J. Bosker (2012) Multilevel Analysis: An Introduction to Basic and Advanced Multilevel Modeling, 2nd ed. (London: Sage PUblications)

Tanaka, Tomomi, Colin F. Camerer, and Quang Nguyen (2010) 'Risk and Time Prefer- 
ences: Linking Experimental and Household Survey Data from Vietnam.' American Economic Review 100(1), 557-571

Vieider, Ferdinand M., Abebe Beyene, Randall A. Bluffstone, Sahan Dissanayake, Zenebe Gebreegziabher, Peter Martinsson, and Alemu Mekonnen (2018) 'Measuring risk preferences in rural Ethiopia.' Economic Development and Cultural Change 66(3), 417-446

Vieider, Ferdinand M., Mathieu Lefebvre, Ranoua Bouchouicha, Thorsten Chmura, Rustamdjan Hakimov, Michal Krawczyk, and Peter Martinsson (2015) 'Common components of risk and uncertainty attitudes across contexts and domains: Evidence from 30 countries.' Journal of the European Economic Association 13(3), 421-452

Vieider, Ferdinand M., Peter Martinsson, Nam Pham Khanh, and Nghi Truong (2019) 'Risk Preferences and Development Revisited.' Theory \&3 Decision 86, 1-21

von Gaudecker, Hans-Martin, Arthur van Soest, and Erik Wengström (2011) 'Heterogeneity in Risky Choice Behaviour in a Broad Population.' American Economic Review $101(2), 664-694$

Wilson, M., and M. Daly (1997) 'Life expectancy, economic inequality, homicide, and reproductive timing in Chicago neighbourhoods.' BMJ : British Medical Journal 314(7089), 1271-1274

Zeger, Scott L., Kung-Yee Liang, and Paul S. Albert (1988) 'Models for Longitudinal Data: A Generalized Estimating Equation Approach.' Biometrics 44(4), 1049-1060

Zhong, Songfa, Soo Hong Chew, Eric Set, Junsen Zhang, Hong Xue, Pak C. Sham, Richard P. Ebstein, and Salomon Israel (2009) 'The Heritability of Attitude Toward Economic Risk.' Twin Research and Human Genetics 12(1), 103-107 